Comparative Philosophy Volume 12, No. 1 (2021): 111-124

Open Access / ISSN 2151-6014 / www.comparativephilosophy.org

https://doi.org/10.31979/2151-6014(2021).120110

\title{
REFLECTION AND EMOTIONAL WELL-BEING IN NIETZSCHE AND ZHUANG ZI
}

\author{
DANESH SINGH
}

\begin{abstract}
Nietzsche and Zhuang Zi both believe that the supposed value of certain emotions they deem harmful should be questioned and that reflection can be utilized to change the emotions. They intend to disabuse those of their respective times of conventional morality, with the aim of achieving a state in which negative moral emotions are eliminated and a more natural way of life is embraced. Specifically, Nietzsche examines guilt, a remnant of an ascetic morality endorsed by the religious elite; Zhuang Zi, similarly, considers grief, a moral emotion tied to traditional culture and endorsed by Confucian morality. Living naturally involves the absence of psychic conflict that accompanies negative emotions; it also involves a psychological ease within ourselves and with the world.
\end{abstract}

Keywords: comparative ethics, emotions, Nietzsche, reflection, Zhuang Zi

Nietzsche's and Zhuang Zi's (莊子) normative projects involve fostering the right kinds of psychological and emotional lives. Both believe that the supposed value of certain emotions they deem harmful should be questioned and that reflection can be utilized to change the emotions. They intend to disabuse their readers of pernicious social influences of their respective times, with the aim of achieving a state in which strong negative emotions are eliminated. Through reflection, individuals recognize that conventional thinking is based on prejudices that preclude the possibility of living naturally. Living naturally involves the absence of psychic conflict that accompanies the negative emotions; it also involves a psychological ease within oneself and with the world. The aim of the present study is to draw out a comparison of the role of reflection and the overcoming of negative emotions in facilitating emotional change. I will focus on the elimination of two moral emotions in particular: Nietzsche examines guilt, a remnant of an ascetic morality endorsed by the religious elite; Zhuang $\mathrm{Zi}$, similarly, considers grief, a moral emotion tied to traditional culture and endorsed by Confucian morality.

SINGH, DANESH: Assistant Professor of Academic Literacy and Linguistics, Borough of Manhattan Community College (CUNY), USA. Email: danesh.singh@gmail.com 


\section{NIETZSCHE, ZHUANG ZI, AND EMOTIONAL WELL-BEING}

There have been numerous studies comparing the philosophical visions of Nietzsche and $\mathrm{Zhuang} \mathrm{Zi}$. The studies that have most informed the present investigation are those that highlight the theme of a psychological change in the self, namely the comparative work of Parkes (1983, 1989, 2013) and Shang (2006). Parkes' comparative studies of Nietzsche and Zhuang Zi have been important to the present study, insofar as, for Parkes, Nietzsche and Zhuang $\mathrm{Zi}$ are understood as "psychologically acute philosophers intent of effecting a transformation of our ideas of self and world - and thereby of ourselves" (Parkes 1983, 235).

Parkes articulates self-cultivation in terms of a psychological reorientation that can be explained in terms of a three-part process: immersion, detachment, and reintegration (Parkes 1983, 245-46). Immersion is characterized as a state in which individuals are in some sense not fully formed. Immersed individuals participate unconsciously in society and the world of nature. In the detachment stage, individuals withdraw from the taken for granted world of objects and people and reflect on and interrogate social norms and tradition. In the last stage of reintegration, there is a return to the world, but now the mode of orientation for individuals is one that is reflective and self-conscious. This leads Parkes to say that psychological change for Nietzsche and Zhuang Zi is fundamentally about "a particular way of being in the world - a mode of involved yet reflective participation in the world rather than of detached observation of the cosmos [his italics]" (Parkes 1983, 237). Parkes also highlights in his comparison that Nietzsche and Zhuang Zi both challenge their readers to relate to nature appropriately (Parkes 1989; Parkes 2013). We fail to relate to nature appropriately, in two senses: first, we relate poorly to the natural world, and second, to ourselves as human creatures (Parkes 1989, 80).

Although Parkes is right to cast the three-stage process as a means to getting back in touch with the natural world and with ourselves, he does not discuss the emotions and their role to this broad project. In the present study, I hold the view that Nietzsche and Zhuang Zi believe that negative moral emotions, like guilt and grief respectively, are an obstacle to living naturally. They believe that individuals are emotionally damaged, in ways that reflect a break with living naturally (see Singh 2015). They encourage their readers to return to a more natural way of life in which they eliminate negative emotions as well as their accompanying beliefs, which are mistakenly asserted as true. The completion of their respective visions involves individuals getting in touch with their natural temperaments and adopting a mode of orientation in which they experience a lack of psychic conflict and instead experience psychological ease.

In his comparative study of Nietzsche and Zhuang Zi, Shang focuses on the concept of "religiosity," which "emphasizes the need for human liberation from all traditional values in order to affirm life" (Shang 2006, 6). He explains how both Nietzsche and Zhuang $\mathrm{Zi}$ critique existing conventions, concepts, and normative standards to ultimately affirm life (Shang 2006, 160). What results from their critique is a view of human liberation. This view adopts the point of view of religiosity, which says that human life is of paramount value, since it is sacred and divine. Shang's concept of the 
affirmation of life seems to concern a state of being favorably disposed to human existence once traditional values have been cleared away. Shang himself calls the affirmation of life a "religious feeling" towards life which provides meaning as well as a sense of the sacred or the sublime (Shang 2006, 1). As with Parkes, Shang does not offer a treatment of the emotions, even as affirmation has a broadly affective quality, similar to emotions. I follow Shang in offering a comparative reading of Nietzsche and Zhuang $\mathrm{Zi}$ that encapsulates their philosophies in terms of overcoming traditional thinking to lead lives that positively dispose us to the world and to ourselves, on an affective level. I hope to expand upon the insights in Shang's study concerning Nietzsche's and Zhuang Zi's critique of traditional morality by discussing the pernicious nature of the moral emotions of guilt and grief, respectively.

As I already mentioned, Parkes' brief discussion of the three-step process of immersion, detachment, and reintegration as stages along the path to radical change is helpful, but he does not give much detail about each stage. Yearley has offered a more complete account of the stages or tiers of self that provide "desires to act" or "impulses to move" in connection to Zhuang Zi's thought and ancient Chinese thought generally (Yearley 1996, 153). I apply the dispositional, reflective, and transcendent motivations to Zhuang Zi's as well as to Nietzsche's respective views about the overcoming of certain negative emotions. Aspects of this account resemble Frankfurt's view of a hierarchical self, with second-order desires either incorporating or rejecting first-order desires (Frankfurt 1971). Both Nietzsche and Zhuang Zi hold that second-order beliefs and desires have the potential to transform the moral self, insofar as they enable individuals to reflect on the value of certain emotions. Nietzsche and Zhuang Zi believe that the accomplishment of their visions require a radical revision of everyday emotional responses indicative of their respective times.

First, dispositional motivations trigger an unreflective knee-jerk reaction (Yearley 1996, 153). Some dispositional motivations originate in the biological aspects of human life, such as hunger, but Nietzsche and Zhuang Zi highlight the dispositional emotions that are socially acquired and construct conventional thinking and feeling, such as guilt and grief, respectively. According to both thinkers, the inculcations of moral emotions provoke certain unreflective ways of being oriented in the world. Ultimately, these negative emotions are pernicious because they alienate individuals from the natural, creating conflict both within the self and with the world. The goal is to become aware of these mistaken emotions, these interpellations, and undergo a process of unlearning them.

Second, in addition to dispositional motivations, humans also possess reflective motivations; these express a desire to have different motivations than the ones characterized as dispositional (Yearley 1996, 154). For instance, I may have a dispositional motivation which makes me easily prone to the sort of anxiousness Zhuang $\mathrm{Zi}$ believed to be commonplace in the world he lived in, for instance. But I may step back and, on reflection, decide that I would rather be the kind of person that can be on an even keel with all things, for I know that this way of life allows me to harmonize with the world. I may then resolve to try and make a change in my life. 
Reflection provides the possibility for a change in my emotional life, but, of course, not without some resistance or some degree of intentional willing, at least at the start.

Yearley points out that reflective motivations produce division within the self (Yearley 1996, 154). This aspect of Yearley's view is reminiscent of Frankfurt's hierarchical model of self (Frankfurt 1971). While a part of the self is inclined toward the dispositional motivations to act in accordance with deeply engrained habits, the reflective motivations may lead people to change their way of feeling over a protracted period. Reflective motivations may of course fail to bring about any change in one's emotional life at all. To return to my earlier example, I may, with some struggle, resist the temptation to fall prey to my anxiety. Alternatively, through a gradual process of self-cultivation, I might reform myself in such a way that I hardly experience intense feelings of anxiety any longer. Reflective motivations have the potential to lead to a radical change in the self.

Third, when one has been completely altered by these reflective motivations, transcendent motivations begin to operate in the self (Yearley 1996, 154). These motivations allow for the full expression of Nietzsche's and Zhuang Zi's respective visions. For both Nietzsche and Zhuang $\mathrm{Zi}$, transcendent motivations lead to the dissolution of dispositional emotions, such as guilt and grief. By transcendent, I refer to a state in which individuals become fully attuned to the psychological and emotional states endorsed by each thinker; individuals experience the world in ways that initially seemed to be far beyond their normal capacities (Yearley 1996, 154). The transcendent motivations that result from the overcoming of guilt and grief respectively amount to a more natural relationship in which individuals experience a psychological ease, characterized by the absence of emotions that bring about conflict and strife within the self and with the world.

\section{NIETZSCHE, REFLECTION, AND THE EMOTION OF GUILT}

Nietzsche presents a complex picture of the self or soul and its parts in his thought. We must know its details to understand his views about the emotions and how emotional change is possible. According to Nietzsche, the soul is composed of sub-personal elements he calls drives. These drives compete with one another for dominance over the soul. Nietzsche believes that reason plays a restricted role in enabling one drive to dominate over another. He writes that when we reflect on reasons for and against a given evaluation, these reasons are only able to "take the side" of an intentional drive (Nietzsche 1997, 65). While what Nietzsche, in the same passage, calls the "intellect" can give support to an intentional drive, it ultimately operates through a drive. In other words, for Nietzsche, reflective motivations do not arise from themselves; they have sentiment as their source. But regardless of its source, reflective motivations can nonetheless be employed to interrogate dispositional emotions, like guilt.

Nietzsche opposes Plato's view that reason can bring harmony to the self. Clark and Dudrick offer a reading that casts Nietzsche's view of the soul as a refinement of Plato's soul hypothesis (Clark and Dudrick 2012, 155-175). Nietzsche accepts the notion that the emotions can be understood in terms of an internal structure, the causal 
properties of which are explained in terms of the interrelations of its parts $(2012,167)$. Plato claims that the soul's main elements are reason, spirit, and appetite (Clark and Dudrick 2012, 166). Reason is the part that calculates and loves to learn and is given the role of forming beliefs about the good. It tells the soul what goals are worth pursuing and which appetites are worth satisfying. Spirit is the part of the soul that desires victory and honor, and it must be used by reason to subdue appetite. Appetites have their own ends and objects toward which individuals can be compelled apart from any judgment of the good.

According to Clark and Dudrick, Nietzsche's conception differs from Plato's, in that Nietzsche converts appetites into drives and translates spirit into will to power, making it a property of all drives $(2012,167)$. Since the only elements of the self that provide a primary source of motivation are the drives, Nietzsche thinks that reason cannot provide an independent source of motivation (Clark and Dudrick 2012, 167). While Nietzsche's view of the self seems to suggest that embodied drives, as part of the whole organism of the self, can reason and evaluate, this ability is not a faculty independent of the drives themselves.

Plato's theory of the soul is different than Nietzsche's. On Plato's view, an individual desire for the good is described in terms that preclude the appetites. Reason knows and even seeks the good without being influenced in any way by the appetites. It is the case that reason is moved by desire, but as Clark and Dudrick point out, this is a desire of reason's own, rather than a desire whose source is appetite $(2012,172)$. As well as denying that reason has desire of its own, Nietzsche opposes the idea that reason can operate in a fashion that is completely independent of the appetites and the emotions; this is because they underlie all perceptual experience of the world. Nietzsche believes instead that there is always a perspective seeing that is constituted by the "affects," and even if individuals could somehow disengage from them, it would amount to a "castrating" of the intellect, for emotional states play an indispensable role in all knowing (Nietzsche 2000, 555).

Even as Nietzsche refines Plato's theory and redefines reason's role in the structure of the soul, reason and reflection continue to play a significant role in his view of emotional change. Without the intellect, individuals cannot engage reflective motivations and employ reason to decide where to set their sights; they are, in other words, unable to hold themselves to certain standards of value. Nietzsche's vision, which involves unlearning dispositional emotions such as guilt, is not possible without reflection, since without it, individuals would be unable to cultivate temperaments and emotions expressive of Nietzsche's vision. Nietzsche explains how his philosophers offer up a critical analysis of the existing values of the time to legislate new values and overcome the past and present (Nietzsche 2000, 326). Nietzsche's project of eradicating dispositional emotions is conceived of in terms of unlearning existing morality, to create the conditions for the transcendent emotions. In The Case of Wagner, Nietzsche explains what separates him from his foil Wagner (Nietzsche 2000, 611). Nietzsche acknowledges that he, like Wagner, is a product of the current times. Nietzsche does not deny that historical circumstances bear on who he is, but he believes that he and 
like-minded philosophers can engage in reflection to actively resist the dispositional motivations that are part and parcel of conventional morality.

Even as Nietzsche believes that the overcoming of conventional morality is achievable, he recognizes its difficulty as well. Katsafanas accurately understands Nietzsche to be complicating a straightforward but naïve notion of reflection as operating independently of the affects and emotional states (Katsafanas 2013, 752). The emotions structure what is perceptually salient in a given situation and continue to do so, even in the midst of reflection. (Katsafanas 2013, 752). Katsafanas takes Nietzsche to be saying that, when individuals engage in reflective motivations, their perception is often denied access to the emotions that underlie their experience such that the emotions operating in the background are not transparent (Katsafanas 2013, 741). At the same time, Katsafanas also believes that Nietzsche would say that reflective detachment from emotions is feasible through hard, self-critical work (Katsafanas 2013, $751 \mathrm{fn} 39$ ). Nietzsche would say that it is possible, though difficult, for moral emotions such as guilt to be interrogated and overcome. Nietzsche investigates the moral emotion of guilt and the "metaphysics of the hangman" that is tied up with it, as we will see. He encourages his readers to critically investigate the effects of guilt on our perceptions and behavior, so that we might overcome guilt and pave the way to emotional well-being.

For Nietzsche, the dispositional emotions reflected in conventional morality are based on pernicious emotions that express ascetic ideals. Ascetic ideals exist in several cultures, including South Asian culture; Nietzsche, however, was concerned with the Christian tradition mostly, the source of which originates in Judaism. Acetic ideas are composed of norms that place value on states of self-denial in which individuals relinquish the satisfaction of basic human desires (Leiter 2002, 246). These desires include those for sexual gratification, or wealth and prestige, as well as ordinary sensual and rapacious desires, whose cessation comes with the possession of the object in question (Leiter 2002, 246). For Nietzsche, individuals increase in strength when they engage in these basic desires. Nietzsche opposes ascetic ideals not because they involve tremendous self-restraint, but rather because they devalue the worth of life itself. As Janaway has explained $(2007,146)$, ascetics may increase in power over themselves, but at the same time they give up their natural strength, thus thwarting psychological well-being. Natural strength is relinquished insofar as there is conflict in the psyche. Ascetics are sick and conflicted in that they are split against themselves by deriving value precisely in denying themselves.

Nietzsche discusses a number of emotions that are expressions of the ascetic ideal. In the Third Section of the Genealogy of Morals, he gives a list of affective or emotional states that ascetic priests have "pressed in their service" for the purpose of manipulating people: anger, fear, voluptuousness, revenge, hope, triumph, despair, and cruelty (Nietzsche 2000, 575). While Nietzsche does not mention guilt in this list, he has much to say about it in the Genealogy and sees guilt as tied up with other emotional states listed. He also offers a treatment of guilt in connection to what he calls the "metaphysics of the hangman" in Twilight of the Idols (Nietzsche 1968, 499-500). It is there that Nietzsche rejects a notion of agency that understands the will as causa sui, the idea that 
the will can be self-caused, rather than be conditioned by other prior causes. If there is such a thing as a moral action that is self-caused, then moral actions can in fact be freely willed. But Nietzsche believes that this is impossible; therefore, agency that depends on a notion causa sui is also impossible (Nietzsche 2000,218).

In his discussion of the metaphysics of the hangman in Twilight, Nietzsche notes that the theory of free will provides a basis for making individuals punishable for their actions. The existing metaphysical view of freedom sets the stage for holding individuals responsible for their actions, thereby also making them guilty for wrongful behavior and marking them as evil. According to this perspective, the main concern is not to avoid certain actions but instead to exact revenge on evil people (Moeller 2006, 130).

Nietzsche notes that the paired concepts of freedom and guilt were invented by the religious elite for the purposes of judging and punishing freely choosing sinners. The "metaphysics of the hangman" contaminates what Nietzsche refers to as the "innocence" of becoming. In The Antichrist, Nietzsche associates the innocence of becoming with the "natural concepts of cause and effect" (Nietzsche 1968, 595). As Nietzsche puts it, "When, through reward and punishment, one has done away with natural causality, an anti-natural causality is required: now everything else that is unnatural follows" (Nietzsche 1968, 595). Nietzsche is saying here that there is no moral world order, but only a causal world order in which things happen not as rewards and punishments for actions but rather as part of an indifferent and impersonal process of the laws of nature (Leiter 2019, 83).

When individuals live in accordance with the innocence of becoming, they have a relationship with the world that enhances human strength, in that it precludes the psychic conflict that accompanies guilt. The concept of becoming opposes a notion of individual responsibility that makes possible a notion of punishment. Nietzsche sees the metaphysics of the hangman to be pernicious, and his overcoming of conventional morality will eradicate belief in the concept of guilt, as it has developed in the Christian tradition. Nietzsche's discussion of the metaphysics of the hangman is meant to encourage individuals to question the value of guilt. When individuals question its value, they take a first step in extricating themselves from its grip as it expresses itself in their emotional lives. In the place of the hangman and guilt, Nietzsche endorses an innocence in which individuals possess emotional responses that give the right proportion to their level of responsibility for how their lives have turned out. They understand that taking some degree of responsibility for their actions is appropriate, but also know that luck and contingency have had a role to play in their lives. Importantly, they do not judge themselves as evil sinners worthy of punishment; instead, they merely judge their actions as simply good or bad. The transcendent motivation that is meant to replace the dispositional emotion of guilt amounts primarily to the absence of guilt and a return to a more natural state in which individuals experience psychological ease within the self and with the world. 


\section{ZHUANG ZI, REFLECTION, AND THE EMOTION OF GRIEF}

In the same way that a treatment of the soul is key to Nietzsche's thought, an understanding of a cluster of concepts relating to the self, including qing (pernicious beliefs/emotions, 情) and qi (energies, 氣), as well as shi-fei (approval versus rejection, 是非), is crucial to a proper understanding of Zhuang Zi's thought.

Fraser has offered a compelling reading of the relationship between qing, qi, and shi-fei in Zhuang Zi's philosophy. In Zhuang Zi's time, emotions were understood as states of qi that constitute qing. Zhuang Zi employs the metaphor of "bonds" and "ties" to describe a state of strife and conflict within oneself and with the world. The metaphor is meant to describe how certain unnatural orientations in the world, manifested in having certain evaluations, bind individuals to things, which prevents them from moving smoothly and effectively in their environment (Fraser 2011, 103). The psychophysical explanation of these kinds of bonds, according to Fraser, is that $q i$ becomes fixated on some approved or disapproved (shi-fei), preferred or disliked (hao$w u$ 好惡), intentional object (Fraser 2011, 103-104). This fixation produces pernicious emotions that are keyed to approvals or disapprovals whose source is conventional morality. Daoist sages possess $q i$ that flows freely through the heart and body, enabling a capacity to adapt fluidly and flexibly in any situation. Attainment of the Way (dao 道) is achieved precisely when individuals both disabuse themselves of conventional morality, which is related to the artificial and human (人 ren), and attune themselves to the patterns inherent in the structure of the universe, which are natural (tian 天 and $z i$ ran 自然).

Importantly, for Zhuang $\mathrm{Zi}$, the term qing itself refers not just to emotions, but also to beliefs or judgmental attitudes asserting the truth or falsity of a state of affairs. While there is a seeming puzzle as to why and how qing would refer to two different mental states, the puzzle is resolved by recognizing that for Zhuang $\mathrm{Zi}$, beliefs and emotions are closely bound up with one another (Chong 2010,40-41). Zhuang Zi suggests that qing has a cognitive component (Zhuang Zi 1956, 5/52-54, Watson 1968, 75; Zhuang Zi 1956, 5/55-58, Watson 1968, 75-76). In one passage, qing is understood in terms of letting right and wrong (shi-fei) do psychological harm. The Daoist sage can attain the Way precisely because he has no qing: "Since he doesn't have the qing of a man, right (shi) and wrong (fei) cannot get at him" (Zhuang Zi 1956, 5/54, Watson 1968, 75).

In another passage, Zhuang $\mathrm{Zi}$ has a conversation with Hui Zi. Zhuang $\mathrm{Zi}$ also says here that the Daoist Way is achieved when individuals have no qing, since by having no qing, "a man doesn't allow likes (hao) or dislikes (wu) to get in and do him harm. He just lets things be the way they are and doesn't try to help life along" (Zhuang Zi 1956, 5/57-58, Watson 1968, 75-76). Qing here refers to beliefs and emotions that are the product of unnatural social norms. Underlying these layers of socialization is a more natural state of being in which individuals can easily accord with the Way. Further, when Zhuang Zi encourages individuals to have no qing, his prescription is made with the recognition that reflective drives can be engaged for individuals to ultimately rid themselves of the beliefs and attitudes that underlie dispositional emotions. Once individuals are disabused of dispositional emotions and the conventional thinking that 
accompanies them is undermined, transcendent motivations in the form of embodied activity can come into play, paving the way for the completion of Zhuang Zi's vision.

As with Nietzsche, Zhuang $\mathrm{Zi}$ understands emotions as giving rise to perceptual experiences that color the way individuals see the world. Chong recognizes that for Zhuang Zi, emotions imply ways of perceiving the world and how events in it affect us (Chong 2010, 41). He identifies Zhuang Zi's position with that of the cognitive view of the emotions, since Zhuang $\mathrm{Zi}$ believes that emotional responses are composed largely or primarily of cognitive content. Chong's interpretation understands beliefs to reinforce emotions that are often counterproductive to psychological and emotional well-being. While eliminating beliefs may not necessarily successfully change their corresponding emotions, Zhuang $\mathrm{Zi}$ seems to think that in interrogating our beliefs there is at least the potential for a change in our emotional lives.

Chong's ascription of the cognitivist view to Zhuang $\mathrm{Zi}$, namely the view that emotions are based largely or primarily on cognitive content, does not imply that Zhuang Zi endorses lacking an emotional life altogether. In fact, Zhuang Zi seems to advocate having an emotional life, albeit one that is devoid of intense emotions. Zhuang Zi himself offers a list of human emotions fundamental to human life: joy ( $x i$ 喜), anger ( $n u$ 怒), grief ( $a i$ 哀), delight (le 樂), and worry (lü 慮). He says that these basic emotions "are the means by which we live." (Zhuang Zi 1956, 2/13-14, Watson 1968, 37-38). The existence of the basic emotions, according to Zhuang Zi, is, like anything else, simply an expression of the transformation of things ( $h u a$ 化), a state of affairs in which there is constant change. It seems that for Zhuang $\mathrm{Zi}$, these basic emotions have a cognitive component, but their cognitive content is such that it does not lend itself to strong emotions. The basic emotions and their accompanying beliefs, then, fall on the side of the natural (tian, zi-ran) rather than the human (ren).

Once individuals rid themselves of intense emotions, they can become what Fraser calls "virtuosos," a name that is fitting, given that this psychological state often occurs in the virtuosic performance of skills or arts (Fraser 2011, 100). Daoist virtuosos adapt fluidly and flexibly to situations and maintain a state in which an individual's $q i$ is in perfect equilibrium. Fraser's examples involve athletes, including tennis and basketball players. Whether players have scored a point or committed an error, they do not dwell on what has happened. They experience only weak emotional responses; since they always maintain equanimity, they shift focus to the next shot or play (Fraser 2011, 100). When individuals cease to think and act in accordance with evaluations that express shi-fei attitudes, they experience a state that Csikszentmihalyi (1990) calls "flow" experience. One of the distinctive features of this aspect of phenomenological experience, according to Csikszentmihalyi, is that individuals become absorbed in whatever they are doing, and their activity is spontaneous. While in normal life, individuals evaluate critically the reasons for acting. In flow experience, "there is no need to reflect, because the action carries us forward as if by magic" (Csikszentmihalyi 1990, 54).

Indeed, for Zhuang Zi, psychological and emotional well-being is achieved in those moments when individuals cease to engage the reflective motivations. Zhuang $\mathrm{Zi}$ 
believes that reflection of the kind that enables distinctions between fixed standards of right and wrong precludes, rather than facilitates, pursuit of the Way (dao). Zhuang Zi encourages us to emulate the "men of ancient times" who ceased to make fixed distinctions between right and wrong. (Zhuang Zi 1956, 2/40-42, Watson 1968, 41; see Slingerland 2003, 176-182). For Zhuang Zi, plans and schemes (mou 謨) inevitably serve as an obstacle to attaining the Way (Zhuang Zi 1956, 5/52, Watson 1968, 75; Zhuang Zi 1956, 6/4, Watson 1968, 77). It is for this reason that individuals must eventually fast the mind (xin-zhai 心齋) of and ultimately forget (wang 忘) their shifei prejudices (Zhuang Zi 1956, 4/26, Watson 1968, 57; Zhuang Zi 1956, 6/89-93, Watson 1968, 90-91), as they shed the layers of socialization that have previously shaped their ways of thinking and feeling.

Although the completion of Zhuang Zi's vision involves unreflective embodied activity, we should not overlook the extent to which reflection plays a central role in Zhuang Zi's vision. Before one becomes a virtuoso, aspirants of the Way must activate their reflective motivations by questioning conventional thinking and their corresponding emotions. Zhuang Zi suggests that reflection is unique to human beings. Human beings are essentially different than nonhuman animals in their ability to engage in reflection. Unlike other animals, humans can also alienate themselves from nature. Zhuang $\mathrm{Zi}$ would say that most people in his time lead artificial lives that take them away from a more natural state. On the other hand, humans are also able to know and understand nature and their relationship to it (Cooper 2018, 51). Zhuang Zi's approach resembles Nietzsche's in that both ask their readers to reflect on the state and value of their current emotional lives, with the hope that they may conceive possibilities greater than what are currently available to them. Also, like Nietzsche, Zhuang Zi encourages his readers to understand the greater workings of nature and our proper and natural relationship to it.

Zhuang $\mathrm{Zi}$ believes that what individuals see when they engage in reflection is contrary to what makes for a compelling life. Even though the second inner chapter in Zhuang-Zi is known for giving stunning theoretical arguments about the nature of language and knowledge, Zhuang $\mathrm{Zi}$ also has a practical goal in mind of awakening us to our situation (see Chen 1985). As Zhuang Zi puts it in that chapter, most people "use their minds in strife," emotionally invested in beliefs and practices that do not easily lend themselves to a life of emotional equanimity (Zhuang Zi 1956, 2/10, Watson 1968, 37). Zhuang $\mathrm{Zi}$ goes so far as to liken human life to a galloping horse that cannot be stopped (Zhuang Zi 1956, 2/18-19, Watson 1968, 38). "Is he not pathetic?" Zhuang Zi asks about the individual who engages in fruitless toil. "Sweating and laboring to the end of his days and never seeing his accomplishment, utterly exhausting himself and never knowing where to look for rest — can you help pitying him?" (Zhuang Zi 1956, 2/19, Watson 1968, 38).

Zhuang $\mathrm{Zi}$ believes that individuals often become lacerated and grinded by their entanglements in the world, busily hustling around in a chase after things they perceive as valuable but in fact are not. Zhuang $\mathrm{Zi}$ asks individuals to reflect on their lives; he invites them to consider what they are seeking after and doing, and what they ultimately gain from their pursuits. Specifically, when Zhuang Zi writes that most people toil their 
entire lives and fail to receive any real gain from it, they are prompted to consider the actual worth of this mistaken way of life. In urging individuals to raise the issue of the value of the lives they lead, Zhuang $\mathrm{Zi}$ attempts to awaken those in his time to the circumstances they find themselves in. He hopes to reveal to them that their lives could be different and strives to make them privy to his Daoist alternative.

Zhuang Zi's vision calls for individuals to employ a longitudinal view as opposed to a snapshot view of nature, to encourage them to see the big picture (Kupperman 2001, 126), a point of view that highlights the interdependence and transformation (hua) of all things. The longitudinal view requires individuals not only to reflect on their lives but to also take on a larger cosmological view in which they see their lives as snapshots of a greater process that precedes and follows their relatively brief existence. Of course, if reflection of this kind accounts for parts of the cosmological process that precedes and follows one's life, then belief in the existence of a permanent and stable identity for things is untenable. This insight is particularly crucial when it comes to reconciling with the death of a loved one.

Zhuang Zi's treatment of death is general and includes reconciling with the death of others as well as with one's own imminent death. For the present purposes, however, I will focus on reconciling with the death of loved ones and the emotions relevant to it, especially the emotion of grief. Grief had played an important role in traditional Chinese culture, prior to Confucianism. That said, Zhuang Zi's criticism on this point is responding to Confucians, who believe that grief has tremendous value in human life. As Berkson has argued, for Confucians, there are two related reasons as to why mourning is an appropriate response to the death of a loved one (Berkson 2011, 196). First, we should mourn because it reflects the nature of the close relationship. Second, we should mourn because it is expressive of one's virtuous character when one does it well. One expresses the virtues of goodness (ren 仁), rightness ( $y i$ 义), and filial piety (xiao 孝) when one grieves the death of a loved one. In short, death, even a "good death" in which a parent lives to old age, is deplorable and regrettable, and so should be mourned.

Zhuang Zi believes that the moral emotion of grief, as Confucians understand the concept, is an inappropriate response toward the death of a loved one. At the same time, Zhuang $\mathrm{Zi}$ lists grief (ai) as a basic emotion that is essential to humanity. To explain away the seeming discrepancy between Zhuang Zi's criticism of Confucianism and acceptance of basic emotions such as grief, we must appeal to the notions of fate (ming 命) and transformation (hua) (Berkson 2011, 199). What separates the basic emotion of grief from what we might call "Confucian grief" is the recognition, from a longitudinal perspective, of these ongoing transformations, as it relates to death. Death, as part and parcel of the transformation of things ( $h u a$ ), is fated (ming), and as such, should be embraced. The Confucian virtues, including the virtues of goodness, rightness, and filial piety, misconceive the proper response to the different phases of this transformation by making Confucian grief central to their view.

Zhauangzi's exercise in reflection concerning the passing of his wife facilities a change in his emotional response to her death (Zhuang Zi 1956, 18/15-19, Watson 1968, 
191-192). When Huizi visits Zhuang Zi to offer condolences, he finds Zhuang Zi on the ground happily singing and pounding on a tub. Huizi asks Zhuang Zi how he could behave in this manner so soon after the death of his wife. Zhuang $\mathrm{Zi}$ replies that immediately after she died, he mourned as anyone would, but later realized that it was inappropriate.

Zhuang $\mathrm{Zi}$ engages in reflective motivations to cultivate an understanding of the transformation of things (hua). The concept of transformation interrogates a view of self as enduring, persistent, and stable. It takes a longitudinal view in which periods of time before and after one leads a life on earth are considered. Specifically, Zhuang Zi looks back at the time before his wife was born, before she had a body, and before she had a spirit. By a process of change, she came into existence. She first acquired a spirit, then later a body, and finally she was born. With another series of transformations, she grew up, and now, with another step in the process of change, she has died. This progression of life and death is not unlike the progression of the seasons. Zhuang $\mathrm{Zi}$ closes by saying, "If I were to follow after her bawling and sobbing, it would show that I don't understand anything about fate (ming). So I stopped" (Zhuang Zi 1956, 18/19, Watson 1968, 192). The story related here illustrates how reflective motivations enable a process of emotional refinement and well-being.

Perhaps the best example of a figure who fully embodies the appropriate Daoist response to a loved one's death is Mengsun Cai. After his mother died, the text recounts that he experienced sadness characteristic of a basic emotion of grief, even as he did not experience Confucian grief. In the story (Zhuang Zi 1956, 6/75-80, Watson 1968, 88 ), Mengsun Cai is shaken by the death of his mother. But although the death of his mother "may startle his body, it won't injure his mind" (Zhuang Zi 1956, 6/79 Watson 1968, 88), since he does not let grief enter "in his heart" (Zhuang Zi 1956, 6/75, Watson 1968, 88). His understanding of the nature of transformation (hua) has awakened him to his circumstances and enables him to grieve appropriately. According to Zhuang Zi, the goal is to neither repress nor indulge the basic emotions (Mollgaard 2007, 132). Emotions are part of ongoing change and transformation and must be managed appropriately. Basic emotions are not incompatible with Zhuang Zi's vision of what it means to lead a life of value and well-being.

In this comparative study, I explore the idea that Nietzsche and Zhuang Zi advocate normative visions that pay particular attention to emotional well-being. I have only been able to discuss guilt in Nietzsche's and grief in Zhuang Zi's thought. In doing so, I have hoped to show the importance of emotional change more generally in each of their respective visions. Both thinkers believe that the emotions have perceptual and evaluative content. For individuals of their respective times to change the way they feel, they must utilize reflection to disabuse themselves of mistaken ways of thinking and perceiving. Through an act of reflection about their existing values, individuals begin to see that conventional thinking is based on prejudices that preclude the possibility of emotional well-being. For both thinkers, a change in evaluations can facilitate a transformation in their emotional lives, leading to more natural state in which individuals experience psychological ease within oneself and with the world. 


\section{ACKNOWLEDGEMENTS}

I wish to thank Charles Goodman, Nicholas Kaldis, and Robert Guay for providing valuable feedback on the core ideas of this article. These ideas originated in my doctoral dissertation, which is a comparative study of the ethical ideas of Nietzsche and Zhuang $\mathrm{Zi}$. I am also thankful to anonymous reviewers of this journal for their helpful comments and suggestions.

\section{REFERENCES}

Berkson, Mark (2011), "Death in the Zhuangzi: Mind, Nature, and the Art of Forgetting", in Amy Olberding and Philip J. Ivanhoe (eds.), Mortality in Traditional Chinese Thought (Albany: State University of New York), 191-224.

Clark, Maudemarie and David Dudrick (2012), The Soul of Nietzsche's Beyond Good and Evil (New York: Cambridge University).

Chong, Kim-chong (2010), “Zhuangzi and Hui Shi on Qing 情”, Tsing Hua Journal of Chinese Studies (New Series) 40.1: 21-45.

Chen, Gu Ying (陳鼓应) (1985), “《齊物論》的理論結構之開展” (Elaboration of thTheoretical Structure of 'Qi Wu Lun'), 江淮論壇 (Jianghuai Forum) 2: 30-39.

Cooper, David E. (2018), "Zhuangzi and the Meaning of Life", in Stephen Leach and Jame Tartaglia (eds.), The Meaning of Life and the Great Philosophers (New York: Routledge), 49-55.

Csikszentmihalyi, Mihaly (1990), Flow: The Psychology of Optimal Experience (New York:Harpur Perennial).

Fraser, Chris (2011), "Emotion and Agency in Zhuangzi”, Asian Philosophy 21.1: 97121.

Frankfurt, Harry G. (1971), "Freedom of the Will and the Concept of a Person", The Journal of Philosophy 68.1: 5-20.

Janaway, Christopher (2007), Beyond Selflessness (New York: Oxford University).

Katsafanas, Paul (2013), "Nietzsche's Philosophical Psychology", in Ken Gemes and John Richardson (eds.), The Oxford Handbook of Nietzsche (New York: Oxford University), 727-755.

Kupperman, Joel (2001), Classic Asian Philosophy: A Guide to the Essential Texts (New York: Oxford University).

Leiter, Brian (2002), Nietzsche on Morality (New York: Routledge).

Leiter, Brian (2019), "The Innocence of Becoming: Nietzsche Against Guilt", Inquiry: An Interdisciplinary Journal of Philosophy 62.1: 70-92.

Moeller, Hans-Georg (2006), The Philosophy of the Daodejing (New York: Columbia University).

Mollgaard, Eske (2007), Introduction to Daoist Thought: Action, Language, and Ethics in Zhuangzi (New York: Routledge). 
Nietzsche, Friedrich (1968), The Portable Nietzsche, trans. Walter Kaufmann (New York: Viking Press).

Nietzsche, Friedrich (1997), Daybreak: Thoughts on the Prejudices of Morality, trans. R.J. Hollingdale (New York, Cambridge University).

Nietzsche, Friedrich (2000), Basic Writings of Nietzsche, trans. Walter Kaufmann (New York: The Modern Library).

Parkes, Graham (1983), "The Wandering Dance: Chuang Tzu and Zarathustra", Philosophy East and West 33.3: 235-250.

Parkes, Graham (1989), "Human/Nature in Nietzsche and Taoism", in J. Baird Callicott and Roger T. Ames (eds.), Nature in Asian Traditions of Thought: Essays in Environmental Philosophy (Albany: State University of New York), 79-97.

Parkes, Graham (2013), "Zhuangzi and Nietzsche on the Human and Nature", Environmental Philosophy 10.3: 1-24.

Shang, Ge Ling (2006), Liberation as Affirmation: The Religiosity of Zhuangzi and Nietzsche (Albany: State University of New York).

Singh, Danesh (2015), "Health as Human Nature and Critique of Culture in Nietzsche and Zhuang Zi”, Comparative Philosophy 6:1: 91-110.

Slingerland, Edward (2003), Effortless Action: Wu-wei as Conceptual Metaphor and Spiritual Ideal in Early China (New York: Oxford University).

Yearley, Lee (1996), "Zhuangzi's Understanding of Skillfulness and the Ultimate Spiritual State", in Paul Kjellberg and Philip J. Ivanhoe (eds.), Essays on Skepticism, Relativism, and Ethics in the Zhuangzi (Albany: State University of New York), 152-182.

Watson, Burton (trans.) (1968), The Complete Works of Chuang Tzu (New York: Columbia University).

Zhuang Zi (1956), A Concordance to Zhuangzi (《莊子引得》Zhuangzi Yingde). Harvard-Yenching Institute Sinological Index Series, no. 20 (Cambridge, MA: Harvard University). 